\title{
Study on Gender Specific Variability of Non-Motor Symptoms Including Cardiovascular, Sexual Disorders, Apathy, Hallucinations, Sleep Disorders and Some Miscellaneous Symptoms of Parkinson's Disease
}

\author{
Anuradha Dehiya ${ }^{1 *}$ and Sarabjeet Singh Rai ${ }^{2}$ \\ 'Assistant Professor, Department of Anatomy, Government Medical College and Hospital, \\ Amritsar - 143001, Punjab, India; anurai81@gmail.com \\ ${ }^{2}$ Consultant Neurologist, Department of Neurology, IVY Hospital, Amritsar - 143001, \\ Punjab, India; sarabjeet3729@gmail.com
}

\begin{abstract}
Introduction: Parkinson's disease is a second most common neurodegenerative disorder after Alzheimer's disease. It affects $1 \%$ of population over age of 50 years. Non-Motor symptoms are common in patients of Parkinson's disease. These remain undiagnosed most of the time. Aim and Objectives: To analyse gender specific, age related and demographic variability of non-motor symptoms (Cardiovascular symptoms, sleep disorder, hallucination, sexual disorders, apathy, pain and miscellaneous symptoms) of Parkinson's disease. Materials and Methods: Present study included 100 cases (66 males and 34 females) of Parkinson's disease presenting at department of neurology, Dayanand Medical College and Hospital, Ludhiana. 30 questionnaires of non-motor symptoms in Hindi and Punjabi were given to patients. Gender, age, duration of non-motor symptoms, Parkinson's phenotype and complete demographic profile of each patient taken into account for study. Thereafter result were statistically analysed for all parameters. Conclusion: It is concluded that mean age and duration of non-motor symptoms were higher in males as compared to females. It was calculated that there was positive correlation of H\&Y with age and non-motor symptoms like Cardiovascular, Sleep related disorder, apathy, pain and miscellaneous symptoms. As H\&Y increases there is increase in frequency and severity of symptoms. There was difference in dominant non-motor symptoms among different genders. Sexual dysfunction and sleep disorders were more prominent in males whereas cardiovascular and miscellaneous like excessive sweating were more in females.
\end{abstract}

Keywords: Parkinson's, Non-Motor, Gender Variability

\section{Introduction}

Parkinson's disease is second most common neurode generative disorder after Alzheimer's disease ${ }^{1}$. It affects 1\% of the population over age of 50 yrs. The typical hall mark features of Parkinson's Disease (PD) is asymmetric onset of bradykinesis, rigidity and resting tremors ${ }^{2}$. The peak age of onset of $\mathrm{PD}$ is $5^{\text {th }}$ decade and its duration of course ranges from 10-25 $\mathrm{yrs}^{3}$. Cause of disease is loss of dopamine neuron in substantia nigra of mid brain ${ }^{4}$. Apart from motor symptoms non-motor symptoms also occur in Parkinson's disease and these are often overshadowed by motor symptoms ${ }^{5}$. Numerous studies have indicated that non-motor symptoms frequently accompanied motor symptoms ${ }^{5}$. Non-motor symptoms of Parkinson's disease include sleep disorder, cardiovascular symptoms, sexual

${ }^{*}$ Author for correspondence 
disorders, apathy, hallucinations and many miscellaneous symptoms. These Non-motor symptoms can be present at any stage of PD including early or premotor phase $\mathrm{e}^{6}$. Despite importance of non-motor symptoms in patients suffering from $\mathrm{PD}$, there is very scanty data available on various parameter of non-motor symptoms of Parkinson's disease in Indian context ${ }^{7}$.

\section{Aims and Objectives}

- To analyse the demographic and age-related variability in cardiovascular symptoms, sleep disorders, hallucination, sexual disorder, apathy, pain and miscellaneous Non-motor symptoms of Parkinson's disease.

- To analyse the gender specific variability of cardiovascular symptoms, sleep disorder, hallucinations, sexual disorders, apathy, pain and miscellaneous Non-motor symptoms of Parkinson's disease.

\section{Materials and Methods}

\subsection{Source and Method of Collection of Data}

The present study included 100 OPD (66 males and 34 females) cases of idiopathic PD from different demographic backgrounds and of both genders of different age group (35-85 yrs) enrolled with Department of neurology, Dayanand Medical College and hospital, Ludhiana. Patients satisfying the UK PD brain bank criteria for idiopathic Parkinson disease were included in study.

\subsection{Validation of Data}

In this present study total 100 patients with diagnosis of Parkinson disease were screened. An independent professional translated the items and another translated to response categories in Punjabi/Hindi. Then a consolidated forward version was produced. This questionnaire then was again translated into English by another professional to check for differences between Punjabi/ Hindi version and the original questionnaire. After a careful review few changes were made and provisional version of questionnaire was finalized. Subsequently this questionnaire was pilot tested and administered to a sample of 20 patients of acute coronary syndrome. After pilot testing a few more changes were made. Then a final version of scale was provided and used in the study. 20 healthy individuals were included as the controls, preferably the family members with similar age groups.

\subsection{NMSS (Non-Motor Symptoms Study)}

The NMSS includes ten domains and total of 30 questions including 19 questions related to Pain, Apathy, Sexual, hallucinations, cardiovascular, sleep related and many miscellaneous symptoms. Present study concerned with Pain, Apathy, hallucinations, cardiovascular, sleep related and many miscellaneous symptoms. NMSS not only assesses whether or not, NMS present but also rates their frequency (0-4) and severity (0-3). If the product of the frequency and severity is 1 or greater, then 1 point is assigned.

The NMSS was specifically designed for the patients to help them in assessing their own symptoms; thus, it was not specifically constructed for care giver's assessment of their patients. The mean of each were taken. Patient individual symptom was compared with respect to age, gender, H\&Y (Hoehn and Yahr) stage, disease duration and subtype (akinetic/tremor predominant).

\subsection{Exclusion Criteria}

Patients with following diagnosis were excluded from study

1. Multi system atrophy

2. DSM 4 criteria of depression

3. Corticobasal degeneration

4. Dementia

5. Dementia with Lewy body disease

6. Progressive supranuclear palsy

7. Frontotemporal dementia

8. History of related head injury

\subsection{Parkinson Disease Non-Motor Symptoms (PDNMS) Questionnaire}

A range of problems listed below were asked for presence/once present and rate them with frequency and severity. The maximum severity and frequency number was 12 and 0 for minimum. Further the NMS 
symptoms were subdivided into various groups as shown below. The complete NMS questionnaire data was obtained and compared between gender match group and statistical analysis spearmen coefficient for correlation was done.

\subsection{Ethical Approval}

Ethical approval was obtained from the institutional review board of Dayanand Medical College and Hospital after submission of study proposal and design.

Table 1. PDNMS Questionnaire

\begin{tabular}{|c|c|c|c|c|c|}
\hline \multirow{2}{*}{ NMS SUBTYPE } & \multirow{2}{*}{ SYMPTOMS } & \multicolumn{2}{|c|}{ YES } & \multicolumn{2}{|c|}{ NO } \\
\hline & & Frequency (0-4) & Severity (0-3) & $(0-4)$ & $(0-3)$ \\
\hline Pain related symptoms & 1. Unexplained pain & & & & \\
\hline Apathy symptoms & $\begin{array}{l}\text { 2. loss of interest in what is happening } \\
\text { around you } \\
\text { 3. unexplained change in weight } \\
\text { 4. feeling anxious, frightened or panic }\end{array}$ & & & & \\
\hline Sex related problem & $\begin{array}{l}\text { 5. feeling less or more interested in } \\
\text { sex } \\
\text { 6. feeling it difficult to have sex when } \\
\text { you try }\end{array}$ & & & & \\
\hline Hallucinations & $\begin{array}{l}\text { 7. seeing or hearing things that you } \\
\text { know or are told are not there } \\
\text { 8. believing things are happening to } \\
\text { you that other people say are not } \\
\text { there }\end{array}$ & & & & \\
\hline $\begin{array}{l}\text { Cardiovascular } \\
\text { symptoms }\end{array}$ & $\begin{array}{l}\text { 9. Feeling light headed, dizzy or weak } \\
\text { when standing from sitting or lying } \\
\text { 10. Falling }\end{array}$ & & & & \\
\hline Sleep related symptoms & $\begin{array}{l}\text { 11. Finding it difficult to stay awake } \\
\text { during activity such as walking, } \\
\text { driving or eating } \\
\text { 12. Difficulty in getting to sleep at } \\
\text { night } \\
\text { 13. Intense, vivid dreams or } \\
\text { frightening dreams } \\
\text { 14. Talking or moving about in your } \\
\text { sleep as if you are acting out of } \\
\text { dreams } \\
\text { Unpleasant sensations in your } \\
\text { leg at night or while resting and a } \\
\text { feeling that you need to move }\end{array}$ & & & & \\
\hline $\begin{array}{l}\text { Miscellaneous } \\
\text { symptoms }\end{array}$ & $\begin{array}{l}\text { 16. Swelling of your leg } \\
\text { 17. Excessive sweating } \\
\text { 18. Double vision } \\
\text { 19. light headedness }\end{array}$ & & & & \\
\hline
\end{tabular}




\subsection{Statistical Analysis}

Spearman's correlation used to analyse correlation of symptoms of Parkinson. It was calculated using Microsoft excel software for calculation purposes.

- Calculation of rho was done. P value was calculated for significance.

- Ratio of Tremor/Akinetic State - Ratio were calculated. If the ratio is more than 0.8 then patient is classified as having tremor prominent. If the ratio less than 0.8 then patient is akinetic dominant.

\section{Observations and Results}

In our study all patients of Parkinson disease had one or more Non-motor symptoms. The number of NMS present in the two-gender group depicted in (Table 2).

Table 2. Number of gender specific non-motor symptoms

\begin{tabular}{|c|c|c|}
\hline \multirow{2}{*}{ No of NMS } & \multicolumn{2}{|c|}{ GENDER } \\
\cline { 2 - 3 } & Female & Male \\
\hline $1-6$ & $10(28.6 \%)$ & $15(23.1 \%)$ \\
\hline $7-10$ & $6(17.1 \%)$ & $10(15.4 \%)$ \\
\hline $11-15$ & $9(25,7 \%)$ & $10(15.4 \%)$ \\
\hline $15-19$ & $1(2,9 \%)$ & $11(16.9 \%)$ \\
\hline
\end{tabular}

Table 3. Mean \pm SD of age/H\&Y score/PD duration $(\mathrm{N}=100)$

\begin{tabular}{|l|c|c|c|}
\hline & $\begin{array}{c}\text { MALE } \\
(\mathrm{N}=65)\end{array}$ & $\begin{array}{c}\text { FEMALE } \\
(\mathrm{N}=35)\end{array}$ & \multirow{2}{*}{ P Value } \\
\cline { 2 - 4 } & Mean \pm SD & Mean \pm SD & \\
\hline AGE (YEARS) & $61.86 \pm 10.14$ & $57.09 \pm 8.576$ & $\mathrm{p}>0.05$ \\
\hline H\& Y & $2.40 \pm 0.746$ & $2.66 \pm 0.802$ & $\mathrm{p}>0.05$ \\
\hline $\begin{array}{l}\text { PD DURATION } \\
\text { (MONTHS) }\end{array}$ & $61.86 \pm 10.13$ & $42.51 \pm 33.7$ & $\mathrm{p}>0.05$ \\
\hline$<0.8$ AKINECTIC & 58 & 30 & $\mathrm{p}>0.05$ \\
\hline $\begin{array}{l}>=0.8 \text { TREMOR } \\
\text { PREDOMINANT }\end{array}$ & 8 & 4 & $\mathrm{p}>0.05$ \\
\hline NMS & $81.58 \pm 51.34$ & $75.374 \pm 45.97$ & $\mathrm{p}>0.05$ \\
\hline
\end{tabular}

Males were having more symptoms as compared to females. This may be due to higher age and duration of Parkinson disease (Table 3).
Table 4. Mean $\pm \mathrm{SD}$ values of non-motor symptoms in males and females

\begin{tabular}{|c|c|c|}
\hline \multirow{2}{*}{ Non-Motor Symptoms } & \multicolumn{2}{|c|}{ GENDER } \\
\hline & FEMALE & MALE \\
\hline $\begin{array}{l}\text { Pain related } \\
\text { - Unexplained pain }\end{array}$ & $3.43 \pm 3.441$ & $3.54 \pm 3.619$ \\
\hline \multirow{3}{*}{$\begin{array}{l}\text { Apathy } \\
\text { - Loss of interest in what is } \\
\text { happening around you } \\
\text { - Unexplained change in } \\
\text { weight } \\
\text { - Feeling anxious, } \\
\text { Frightened or Panic }\end{array}$} & $3.14 \pm 3.291$ & $3.51 \pm 3.532$ \\
\hline & $1.23 \pm 2.302$ & $2.40 \pm 2.983$ \\
\hline & $2.80 \pm 2.959$ & $2.92 \pm 3.285$ \\
\hline \multirow{2}{*}{$\begin{array}{l}\text { Sex disorders } \\
\text { - Feeling less or more } \\
\text { interested in sex } \\
\text { - } \quad \begin{array}{l}\text { Feeling it difficult to have } \\
\text { sex when you try }\end{array}\end{array}$} & $2.91 \pm 3.338$ & $2.00 \pm 2.867$ \\
\hline & $1.60 \pm 2.767$ & $2.37 \pm 2.935$ \\
\hline \multirow{2}{*}{$\begin{array}{l}\text { Hallucinations } \\
\text { - Seeing or hearing things } \\
\text { that you know or are told } \\
\text { are not there } \\
\text { - Believing things are } \\
\text { happening to you that } \\
\text { other people say are not } \\
\text { there }\end{array}$} & $2.37 \pm 2.961$ & $2.05 \pm 2.741$ \\
\hline & $1.71 \pm 2.256$ & $1.86 \pm 3.112$ \\
\hline \multirow{5}{*}{$\begin{array}{l}\text { Sleep related disorders } \\
\text { - } \quad \text { Finding it difficult to stay } \\
\text { awake during activities } \\
\text { such as working, driving } \\
\text { or eating } \\
\text { - Difficult getting to sleep } \\
\text { at night or staying asleep } \\
\text { at night } \\
\text { - Intense, vivid dreams or } \\
\text { frightening dreams } \\
\text { - Talking or moving about } \\
\text { in your sleep as if you are } \\
\text { acting out of dreams } \\
\text { - Unpleasant sensation } \\
\text { in your legs at night or } \\
\text { while resting and feeling } \\
\text { that you need to move }\end{array}$} & $1.97 \pm 2.695$ & $2.11 \pm 2.716$ \\
\hline & $2.11 \pm 3.288$ & $2.94 \pm 3.513$ \\
\hline & $2.26 \pm 2.790$ & $2.46 \pm 2.964$ \\
\hline & $1.80 \pm 2.530$ & $2.08 \pm 2.588$ \\
\hline & $1.60 \pm 2.637$ & $2.38 \pm 3.040$ \\
\hline \multirow{2}{*}{$\begin{array}{l}\text { Cardiovascular symptoms } \\
\text { - Feeling light headedness, } \\
\text { dizzy or weak when } \\
\text { standing from sitting or } \\
\text { lying } \\
\text { - Falling }\end{array}$} & $2.37 \pm 3.465$ & $2.92 \pm 3.663$ \\
\hline & $1.74 \pm 2.536$ & $1.88 \pm 2.601$ \\
\hline
\end{tabular}




\begin{tabular}{|l|c|c|}
\hline Miscellaneous & $2.51 \pm 2.904$ & $3.17 \pm 3.120$ \\
\cline { 2 - 3 } - $\begin{array}{l}\text { swelling of legs } \\
\text { - } \begin{array}{l}\text { Excessive sweating } \\
\text { Double vision }\end{array}\end{array}$ & $3.74 \pm 3.433$ & $3.52 \pm 3.589$ \\
\cline { 2 - 3 } - Light Headedness & $2.11 \pm 3.288$ & $3.18 \pm 3.682$ \\
\cline { 2 - 3 } & $2.74 \pm 3.837$ & $3.03 \pm 3.477$ \\
\hline
\end{tabular}

In present study it was found that in males NMS were noted with higher mean as compared to females which includes unexplained pain, low sexual drive etc. Hallucinations were less common among both genders with least mean $1.71 \pm 2.256$ in females (Table 4). Higher rates of NMS like sleep disorders, cardiovascular symptoms, double vision and light headedness noted in females. Mean \pm SD values for all NMS shown in (Table 4).

Further detailed analysis of individual NMS was done to find NMS correlation with demographic parameters. Their significance shown in (Table 5).
Non motor symptom like falling difficulty in getting to sleep $(\mathrm{p}=0.008)$ at night and swelling in legs $(\mathrm{p}=0.015$ $\& \mathrm{p}=.029)$ had positive correlation with increasing age and disease severity (H\&Y) stage. These symptoms were not having any correlation with disease duration and phenotype of Parkinson disease. As age of Patient with Parkinson disease increases the number of NMS also increases so as H\&Y stage increases. NMS also increases in frequency and severity. NMS like unpleasant sensation in legs and weight change had positive correlation with only H\&Y i.e., as the stage increases the frequency and severity of symptoms increases ( $\mathrm{p}=<0.05)$. There is no correlation with duration and subtype. Whereas NMS like finding difficult to stay awake, intense or vivid dreams, talking or walking in sleep, excessive sweating, light headedness, believing things that are happening to you that other say are not true, feeling more or less

Table 5. Symptoms Spearmen Rho correlation with age/H\&Y stage/PD duration and Parkinson phenotype predominant $(n=100)$

\begin{tabular}{|c|c|c|c|c|c|c|c|c|}
\hline $\begin{array}{c}\text { Spearman's rho correlation } \\
\text { coefficient }\end{array}$ & Age (years) & P value & $\mathrm{H} \& \mathrm{Y}$ & $P$ value & $\begin{array}{l}\text { Ratio of } \\
\text { tremor } \\
\text { and } \\
\text { akinetic }\end{array}$ & $P$ value & $\begin{array}{l}\text { Duration } \\
\text { of PD in } \\
\text { months }\end{array}$ & $P$ value \\
\hline Unexplained pains & $.201^{*}$ & .045 & .185 & .066 & .065 & .517 & .098 & .330 \\
\hline $\begin{array}{l}\text { Loss of interest in what is } \\
\text { happening around you }\end{array}$ & .107 & .289 & $.217^{*}$ & .030 & -.144 & .154 & .027 & .791 \\
\hline $\begin{array}{l}\text { Unexplained change in } \\
\text { weight }\end{array}$ & .169 & .092 & $.229^{*}$ & .022 & .147 & .145 & .041 & .683 \\
\hline $\begin{array}{l}\text { Feeling anxious, frightened } \\
\text { or panic }\end{array}$ & .171 & .089 & .068 & .502 & .136 & .178 & -.023 & .823 \\
\hline $\begin{array}{l}\text { Feeling less or more } \\
\text { interested in sex }\end{array}$ & -.078 & .438 & .067 & .509 & -.148 & .142 & .122 & .226 \\
\hline $\begin{array}{l}\text { Feeling it difficult to have sex } \\
\text { when you try }\end{array}$ & .052 & .605 & $.229^{*}$ & .022 & -.051 & .614 & .088 & .386 \\
\hline $\begin{array}{l}\text { Seeing or hear things those } \\
\text { are not there Believing things } \\
\text { are happening to you that } \\
\text { other people say are not true }\end{array}$ & -.067 .041 & .508 .684 & -.044 .189 & .667 .060 & $-.037-.074$ & .714 .467 & .005 .073 & .958 .469 \\
\hline $\begin{array}{l}\text { Feeling light headed, dizzy } \\
\text { or weak when standing from } \\
\text { sitting or lying }\end{array}$ & $.293^{* *}$ & .003 & $.260^{* *}$ & .009 & -.062 & .543 & .059 & .560 \\
\hline Falling & $-.242^{*}$ & .015 & $.271^{*}$ & .006 & -.073 & .473 & -.069 & .497 \\
\hline $\begin{array}{l}\text { Finding it difficult to stay } \\
\text { awake during activities such } \\
\text { as working, driving or eating }\end{array}$ & .171 & .089 & .169 & .093 & -.157 & .119 & -.027 & .786 \\
\hline
\end{tabular}




\begin{tabular}{|c|c|c|c|c|c|c|c|c|}
\hline $\begin{array}{l}\text { Difficulty getting to sleep at night or staying } \\
\text { asleep at night }\end{array}$ & $.264^{* *}$ & .008 & $.265^{* *}$ & .008 & -.122 & .228 & -.026 & .799 \\
\hline Intense, vivid dreams & -.020 & .842 & .109 & .279 & -.105 & .298 & -.032 & .751 \\
\hline $\begin{array}{l}\text { Talking or moving about in your sleep as if } \\
\text { you are acting out of dream }\end{array}$ & .136 & .176 & .149 & .139 & -.051 & .614 & -.143 & .155 \\
\hline Unpleasant sensation in your legs at night & .133 & .186 & $.207^{*}$ & .039 & .007 & .946 & -.116 & .246 \\
\hline Swelling of your legs & $.243^{*}$ & .015 & $.218^{*}$ & .029 & -.082 & .415 & -.106 & .294 \\
\hline Excessive sweating & .146 & .148 & .139 & .167 & .150 & .137 & .157 & .120 \\
\hline Double vision & $.274^{* *}$ & .006 & $.272^{* *}$ & .006 & -.122 & .226 & -.022 & .832 \\
\hline Light headedness & .153 & .128 & .153 & .128 & -.075 & .461 & .167 & .097 \\
\hline
\end{tabular}

${ }^{* *}$ Correlation is significant at the 0.01 level (2- tailed)

${ }^{*}$ Correlation is significant at the 0.05 level (2-tailed)

interested in sex all had no co-relation with age/H\&Y/ Parkinson phenotype/Parkinson duration. When we further compared system wise Non Motor Symptoms (Table 6), it was found that miscellaneous and cardiovascular symptoms having positive co-relation with age and $H \& Y$ stage $(\mathrm{p}=<0.05)$. Similarly, individual symptom like sexual dysfunctions was having co-relation only with $\mathrm{H} \& \mathrm{Y}$ stage $(\mathrm{p}=<0.006)$ while apathy had positive co-relation with age $(\mathrm{p}=$ $<0.048$ ). Sleep related symptoms are having positive co-relation with age and $\mathrm{H} \& \mathrm{Y}$ stage $(\mathrm{p}=<0.011)$. Pain related symptoms was having positive co-relation only with age ( $\mathrm{p}=<0.045)$.

Hence our result showed that there was variation with respect to system involvement and individual symptoms (frequency and severity) between the genders.

\section{Discussion}

In our study of 100 patients with Parkinson disease there were 66 males with mean age of 61.86 yrs and 34 females with a mean age of $57.09 \mathrm{yrs}$. This mean age is comparable to study done by Chaudhuri et al. ${ }^{8}$, in which mean age of 123 patients was 56.5 . The mean NMS score was $75.77 \pm$ 45.97 in females, and in male the mean NMS Score was $81.58 \pm 51.34$ and mean $\mathrm{H} \& \mathrm{Y}$ score was $2.66 \pm 0.802$ in females and $2.40 \pm 0.746$ in male which was comparable with other study done by Lolekha $\mathrm{P}^{9}$ in which the H\&Y of 83 patients was 2.36 .

There was no gender and demographic difference in our study with respect to duration, H\&Y type and age of onset of PD. The maximum numbers of non-motor symptoms reported were between $28.6 \%$ in females and

Table 6. Spearmen Rho correlation table of symptom phenotype with age and H\&Y Stage

\begin{tabular}{|l|c|c|c|c|}
\hline \multicolumn{1}{|c|}{ Non -Motor Symptoms } & $\begin{array}{c}\text { Spearman's rho coefficient } \\
\text { of Age (years) }\end{array}$ & P value & Spearman's rho coefficient of H\&Y & P value \\
\hline Pain related symptoms & $.201^{*}$ & .045 & .185 & .066 \\
\hline Apathy related symptoms & $.198^{*}$ & .048 & .155 & .124 \\
\hline Sexual related symptoms & .187 & .062 & $.271^{* *}$ & .067 \\
\hline Hallucination related symptoms & .113 & .263 & .006 \\
\hline Cardiovascular symptoms & $.242^{*}$ & .015 & $.251^{* *}$ & .006 \\
\hline Sleep related symptoms & $.253^{*}$ & .011 & $.272^{* *}$ & .011 \\
\hline Miscellaneous symptoms & $.241^{*}$ & $\mathbf{. 0 1 6}$ & .006 \\
\hline
\end{tabular}

${ }^{* *}$ Correlation is significant at the 0.01 level (2-tailed)

${ }^{*}$ Correlation is significant at 0.05 level (2-tailed) 
$23.1 \%$ in males similar to study done by Ravan et al. ${ }^{10}$. The difference between the genders with respect to mean was not significant. These results were consistent with those of study done by Song et al. ${ }^{11}$

The fact came out of present study is that, when NMS correlate with advancing age and disease severity, suggest that only by management of these non-motor symptoms, the average life expectancy of the Parkinson's disease population increases. The study also showed that the number of symptoms correlate with disease duration and severity, as compared with control for complaints of weight loss, hallucinations, anxiety, sexual dysfunction, falling, day time sleepiness, vivid dreams and excessive sweating. There was no significant difference in NMS score by gender with the exception that cardiovascular symptoms and miscellaneous symptoms were more prevalent in women. Sex related disorders increases with H\&Y i.e., severity of disease.

The first report from India and among the few from Asia by Krishnan et al ${ }^{12}$ which compared 174 patients and 128 normal controls to assess the prevalence of NMS and document its relation to disease progression measured by the Hoehn and Yahr Scale, reported a higher frequency of NMS in all domains of patients with PD compared to controls. Women with PD had higher scores in the cardiovascular, sleep/fatigue whereas men had higher scores for sexual domain. Cultural and societal behaviour is probably responsible for under reporting of sexual dysfunction in females. Wang $\mathrm{G}$ et al. ${ }^{13}$ reported a cross sectional study of 82 Chinese patients with PD and found that NMS were common in Chinese patients with PD, with a prevalence of the whole spectrum of NMS being $100 \%$ and the NMSS significantly correlated with disease duration.

On comparison between males and females, unexplained pains was also having higher mean in males (3.45) as compared to females (3.43). This can be due to the higher mean age of study population and it has been proven in study done by Chaudhuri et al. ${ }^{14}$ that the risk of pain increases with age. Excessive sweating was more commonly seen in females 3.74 as compared to males 3.52, the higher mean can be due to more number of post menopausal in our study. Almost all previous studies indicate the predominance of symptoms in sleep and sexual domains. The PRIAMO study reports fatigue, anxiety, insomnia as most common symptoms ${ }^{15}$. Krishnan et al. ${ }^{11}$ reports insomnia and fatigue as being most common symptom followed by miscellaneous symptoms. Choudhuri et al. ${ }^{16}$ found to have low to moderate association with age. In our study it was found that NMS such as sleep, pain, apathy, cardiovascular symptoms and miscellaneous symptom worsened with advancing age and H\&Y stage of the motor symptoms. Sleep related symptoms were more common in both males and females which is highlighted by study done by Shulman et al. ${ }^{17}$ Raven et al. ${ }^{10}$ calculated the disability men score of 0.21 although there was less no of patients in both the group.

\section{Conclusion}

In Present study it was calculated that there was positive correlation of $\mathrm{H} \& \mathrm{Y}$ with age and non-motor symptoms like cardiovascular, sleep, apathy, pain and miscellaneous. As $\mathrm{H} \& \mathrm{Y}$ increases there is increase in frequency and severity of symptoms. There was no correlation of duration and phenotype of Parkinson's subtype with the non-motor symptoms. There found gender specific difference for the non-motor symptoms of Parkinson's disease. There was difference between the dominant symptoms among males and females. Sexual dysfunction and Sleep related disorders were more prominent in males whereas Cardiovascular and miscellaneous symptoms like excessive sweating were more pronounced in females.

\section{References}

1. Przedborski S. Etiology and Pathogenesis of Parkinson's Disease. In: Jankovic J, Tolosa E, eds. Parkinson's Disease and Movement Disorder $5^{\text {th }}$ ed. Philadelphia: Lippincott Williams and Wilkins. 2007; 77-92.

2. The metric properties of a novel non-motor symptoms scale of Parkinson's disease: result from an international pilot study. Mov Discord. 2007; 22: 1901. https://doi. org/10.1002/mds.21596 PMid:17674410

3. Delong MR, Juncos JL. Parkinson's disease and other extrapyramidal movement disorders. Fauci AS, Braunwald E, Kasper DL, Hauser SL, Longo DL, Jamesson JL et al., editors. Harrison's Principles of internal medicine. $17^{\text {th }} \mathrm{ed}$. New York (NY): The McGraw- Hill Companies; 2008.p. 2549-59.

4. Jankovic J, Shannon KM. Movement disorders. Bradley WG, Daroff RB, Fenichel GM editors. Neurology in clinical Practice. $5^{\text {th }}$ ed. Philadelphia: Butterworth- Heinemann, Elsevier; 2008.p. 2081-122. https://doi.org/10.1016/B9780-7506-7525-3.50113-8.

5. Chaudhuri KR, Healy DG, Schapira AHV. NonMotor symptoms of Parkinson's disease: Diagnosis and management. Lancet Neurol. 2008; 5: 314-24. 
6. Tolosa E, Compta Y, Gaig C. The premotor phase of Parkinson's disease. Relat Disord. 2007; 13(suppl): S2-7. https://doi.org/10.1016/j.parkreldis.2007.06.007PMid: 17681839.

7. Dehiyan A and Singh S. Study on Gender Specific Variability of Gastrointestinal, Genitourinary and Depression Related Non-Motor Symptoms of Parkinson Disease. Int jour med and Dent Sci. 2018: 7(2): 1657-1662. https://doi. org/10.18311/ijmds/2018/21429.

8. Chaudhuri KR, Martinez- Martin P, Brown RG, Nordu Y, Slanow, William AJ et al. The metric properties of a novel non-motor symptoms scale for Parkinson's disease: Result from an international pilot study. MovDisord 2007; 22: 1901-11. https://doi.org/10.1002/mds.21596.

9. Lolekha P, Kongkiat K. Non-motor symptoms in Thai Parkinson disease patients: prevalence, manifestation and health related quality of life. Neurology Asia. 2014; 19(2): 163-70.

10. Ravan A, Faiz MR, Chabria S, Gadhari M, Sankhla CS. Non motor symptoms in an Indian cohort of Parkinson's disease patients and correlation of progression of nonmotor symptoms with motor worsening. Neurology India. 2015; 63: 166-74. https://doi.org/10.4103/00283886.156276PMid:25947979.

11. Song Y, Gu Z, An J. Chinese Parkinson study group. Gender difference on motor and non-motor symptoms of de novo patients with early Parkinson's disease. Neurosci. 2014; 35: 1991-6. https://doi.org/10.1007/s10072-014-1879-1.
12. Krishnan S, Sarma G, Sarma S, Kishore A. Do non motor symptoms in Parkinson's disease differ from normal ageing. MovDisord. 2011; 26: 2110-3. https://doi.org/10.1002/ mds.23826 PMid: 21661056.

13. Wang G, Hong Z, Cheng Q, Wang Y, Zhang J, Ma JF et al. Validation of the Chinese non motor symptoms scale for Parkinson's disease: Result from a Chinese pilot study. Clin Neurol Neurosurg 2009; 111: 523-6. https://doi. org/10.1016/j.clineuro.2009.02.005.

14. Chaudhuri KR, Martinez-Martin P, Schapira AH, Stocchi F, Sethi K, Odin $\mathrm{P}$ et al. International multicentre pilot study of the first comprehensive self completed non-motor symptoms questionnaire for Parkinson's disease: The NMS quest study. MovDisord 2006; 21:916-23. https://doi. org/10.1002/mds.20844.

15. Barone P, Antonini A, Colosimo C, Marconi R, Morgante L, Avarello TP et al. The PRIAMO study: A multicentre assessment of non-motor symptoms and their impact on quality of life in Parkinson's disease. Movdiscord 2009; 24: 1641-9. https://doi.org/10.1002/mds.22643.

16. Chaudhuri KR, Tolosa E, Schapira A, Poewe W editors. Non-Motor symptoms of Parkinson's Disease. Oxford, UK: Oxford University Press; 2009; 309-20. https://doi. org/10.1093/med/9780199237234.001.0001.

17. Shulman LM, Taback RL, Rabinstein AA, Weiner WJ. Non recognition of depression and other non-motor symptoms in Parkinson's disease. Parkinsonism Relat Discord. 2002; 8: 193-7. https://doi.org/10.1016/S1353-8020(01)00015-3.
How to cite this article: Dehiya A and Rai SS. Study on Gender Specific Variability of Non-Motor Symptoms Including Cardiovascular, Sexual Disorders, Apathy, Hallucinations, Sleep Disorders and Some Miscellaneous Symptoms of Parkinson's Disease Int. J. Med. Dent. Sci. 2020; 9(1): 1851-1858. 